\title{
Perfil do calouro odontologia
}

\author{
Sônia M. Blauth Slavutzky* \\ Solange Bercht** \\ Leonardo Soares de Lima***
}

\section{Introdução}

$\mathrm{Na}$ tentativa de traçar um perfil atual do calouro da FOUFRGS, realizou-se um questionário com os ingressantes no semestre 91/92, na disciplina Higiene Bucal, do Departamento de Odontologia Preventiva e Social.

\section{Objetivos}

Demonstrar as relaçōes de classe social, origem dos estudantes e seus objetivos ao ingressar na Faculdade de Odontologia da Universidade Federal do Rio Grande do Sul.

Analisar suas atitudes em relação à saúde e relacionamento com filiação e parentesco com dentistas.

\section{Materiais e Métodos}

Este questionário visou desvendar a origem (quanto a escolaridade), sua relação com Odontologia (parentesco e objetivos com o curso) e sua relação com os cuidados de saúde (quanto aos vícios de fumar, beber $\mathrm{e}$ consumir açúcar). Ainda verifica-se através deste questionário a experiência de trabalho (senviço público ou particular), dos mesmos.

\section{Resultados}

Entre as respostas obtidas estāo:

1. Pergunta de número cinco: $O$ que esperas com a profissão no futuro? Enumere em ordem de preferência; cinco eram as alternativas.

a. Ter meios para viver bem, economicamente.

b. Ser um especialista.

c. Poder trabalhar por conta própria.

d. Pretende ter um emprego público.

e. Contribuir para melhoria da saúde dos brasileiros.

Como resposta obtivemos:
- $84,08 \%$ dos calouros classificam as três primeiras respostas $(a, b, c)$ em $1^{\circ}, 2^{\circ}$ ou $3^{\circ}$ lugares. $E 70,45 \%$ colocam as respostas "d" e "e" em $4^{\circ}$ ou $5^{\circ}$ lugares, $e$, ainda, $6,81 \%$ nem mesmo objetivam ter um emprego público ou contribuir para a saúde da população brasileira.

- 13,33 dos calouros possuem emprego público. Destes, todos colocam em $5^{\circ}$ lugar de preferência a resposta "d" (pretende ter emprego público).

- $25 \%$ dos calouros advém de escolas públicas. Destes, $9,09 \%$ pretendem ter emprego público.

2. Parentesco com dentistas:

- 6,0\% não possuem parentes dentistas.

- $17,77 \%$ são filhos de dentistas.

- $8,88 \%$ são irmãos de dentistas.

- $15,55 \%$ são sobrinhos ou primos de $1^{\circ} \mathrm{grau}$ de dentistas.

- $11,11 \%$ são primos em $2^{\circ}$ ou $3^{\circ}$ graus de dentistas.

- $2,22 \%$ são sobrinhos-netos de dentistas.

3. Quanto a pretenção de realizar curso de especialização:

- 42,22\% ainda não decidiram.

- $20 \%$ estão em dúvida. Destes, $44,44 \%$ pensam como opção Cirurgia, 33,33\% Odontopediatria, $33,33 \%$ Ortodontia, e em menores porcentagens Prótese, Endodontia ou Periodontia.

- $37,77 \%$ decidiram. Destes, 58,82 optaram por Ortodontia, $35,29 \%$ por Odontopediatria, $17,64 \%$ por Cirurgia, e em menores porcentagens Prótese e Dentística.

4. Quanto ao consumo de cigarros:

- Dos 45 novos acadêmicos, 4 são fumantes, dois homens (não disseram porque fumam) e duas mu-
Iheres (dizem que fumam por ser um vício, causado por indução social ou de amigos, ou ainda, por ansiedade).

Relaçāo entre parentesco dos calouros do curso de Odontologia 91/92 com clrurgiōes dentistas $x$ o consumo de cigarros

\begin{tabular}{ccc}
\hline Parentesco & \multicolumn{2}{c}{$\begin{array}{c}\text { Não } \\
\text { Fumantes Fumantes }\end{array}$} \\
\hline Filho/Irmāo & $11,11 \%$ & $88,88 \%$ \\
Primo/Sobrinho & $20,00 \%$ & $80,00 \%$ \\
Primo $2^{\circ} / 3^{\circ}$ graus & $00,00 \%$ & $100,00 \%$ \\
\hline TOTAL & $11,76 \%$ & $88,23 \%$ \\
\hline
\end{tabular}

5. Quanto ao consumo de bebidas alcoólicas:

- $48,88 \%$ dos calouros consomem bebidas alcoólicas, sendo $51,61 \%$ das mulheres e $46,15 \%$ dos homens. Destes, $77,27 \%$ bebem socialmente.

Relação entre parentesco dos estudantes de odontologia com cirurgióes dentistas $x$ consumo de bebidas alcob́licas

\begin{tabular}{ccc}
\hline Parentesco & Consum. & $\begin{array}{c}\text { Não } \\
\text { Consum. }\end{array}$ \\
\hline Filho/Irmāo & $66,66 \%$ & $33,33 \%$ \\
Primo/Sobrinho & $40,00 \%$ & $60,00 \%$ \\
Primo $2 \% 3^{\circ}$ graus & $66,66 \%$ & $33,33 \%$ \\
\hline TOTAL & $58,82 \%$ & $41,17 \%$ \\
\hline
\end{tabular}

6. Quanto ao consumo de açúcar: - $96,77 \%$ dos calouros consomem açúcar, e, portanto, 3,23\% não consomem açúcar, o único calouro que não consome açúcar, é so-

* Professora Adjunta, Chefe Depto. de Odontologia Preventiva e Social

** Professora Adjunta do Depto. de Odontologia Preventiva e Social

*ネ* Bolsista de Iniciação Científica da PROPESP UFRGS 
brinha de dentista e usa adoçantes.

\section{Discussão}

A busca de uma saída individual para a crise tem sido a tônica em que vivemos. Não nos estranha portanto, que essa visão predomine na escolha de uma profissão.

Analisando as respostas do questionário apresentado aos calouros de Odontologia, mais uma vez se constata a busca de meios para sobreviver bem economicamente, ser especialista, e trabalhar por conta própria com as opçōes de escolha de $84,08 \%$ dos alunos. Desde o ponto de vista de sanidade mental e supondo que isso represente a maneira de como é veiculada a filosofia de um país capitalista dependente onde o "salve-se quem puder" é a regra geral, não podemos fazer uma crítica moral e essa intençăo, sem entender o contexto brasileiro. A famosa "Lei de Gerson" - Propaganda veiculada na Televisão, que dizia: "Tem que tirar vantagem". - guia das normas de comportamento incutidos em nossos jovens.

O "ser bom profissional", trabalhar para melhorar a saúde pública são vistos e sentidos como tarefas para os menos competentes, pois tem menor remuneração, status social inferior, e principalmente depois da era Collor são cada vez mais desacreditados publicamente.

Os cursos universitários como a Odontologia, no entanto, que tem seu currículo estabelecido de acordo com as normas do Ministério da Educaçăo, formam o profissional de perfil exatamente como o que 0 calouro busca, isto é, priorizando o provado em detrimento ao público, valorizando o individual e o particular $(5,6)$, apesar de gastar recursos públicos, forma profissionais para o mercado, de maneira espelhada nos países mais adiantados do primeiro mundo. A crítica então não cabe aos calouros que passam no vestibular na Universidade Pública, mas sim ao currículo desta Universidade que deveria formar profissionais para trabaIhar em função das necessidades da população do país, mas ao invés disso, forma-os para atender a uma pequena camada da população $(1,4)$.

A partir desse raciocínio, compreendemos que os calouros estão, como todos outros estudantes, "aproveitando-se" da Universidade Pública para, na maioria, resolver "seu" problema de sobrevivência. Isto está de acordo com o currículo traçado pela Universidade, e tudo estaria bem e moralmente aceitável, não fosse pelos dados do último censo do IBGE, de $70 \%$ da população tem ganhos até 5 salários mínimos, o que os torna completamente impossibilitados de pagar por serviços de saúde (Folha de São Paulo, 22/11/91 - Pesquisa Nacional de IB$\mathrm{GE}$, dados preliminares $(2,4)$.

Essa difícil tarefa de demonstrar a realidade vem ao longo dos anos nos colocando, como Departamento de Odontologia Social e Preventiva, à margem dos interesses dos estudantes, pois mostrar-Ihes isso é interferir ou pelo menos perturbar esse mundo de fantasia em relação ao futuro. Isso também nos impede de estar mais próximos dos estudantes, pois a simples lembrança do "público" provoca ogeriza, complexo de culpa para alguns e serve de pilhéria para outros. Isso, contudo, não nos redime de tentar mostrar que os objetivos da Universidade Pública deveriam ser os de buscar soluçōes para o povo brasileiro e não o de simplesmente copiar as soluções encontradas e muitas vezes já abandonadas ou retificadas, em países do primeiro mundo. Acreditamos e temos esperança de que se iniciem novas maneiras de formar estudantes de Odontologia $(3,6)$.

\section{Conclusões}

a. Năo há discordância entre o que busca o calouro de odontologia e o que enfatiza o currículo da Faculdade de Odontologia de Porto Alegre/RS.

b. Os estudantes de Odontologia se preocupam muito pouco com a sua saúde geral, o que é demonstrado pelo alto consumo de fumo, bebidas e açúcar.

c. A Universidade Pública forma o profissional para a clínica privada e a origem dos calouros (mais da metade filhos ou parentes de dentistas), demonstra que a situaçăo se perpetua.

\section{Recomendações}

a. Se faz urgente e necessário uma reavaliação do currículo da faculdade de Odontologia das Universidade Públicas e adaptá-las às necessidades da população.

b. Recomenda-se que as faculdades Privadas de Odontologia formem para os consultórios privados e as Públicas para o restante da população, ou seja, que os recursos advindos da população sejam revertidos em seu favor e năo para beneficiar a camada já beneficiada da população.

c. Recomenda-se que os investimentos em pesquisas sejam gastos em áreas de educaçāo, prevençāo e tecnologia para a saúde pública.

\section{REFERÊNCIAS BIBLIOGRÁFICAS}

01. ALTHUSER, L. Ideologia e aparelhos ideológicos do Estado. In: Fichter, Rosa, M.B. O mito na sala de jantar. Porto Alegre. Movimento, 1985.

02. DONNANGELO, L.; PEREIRA, L. Saúde e Sociedade. São Paulo: Duas cidades, 1976.

03. GRUPPI, L. O conceito de hegemonia em Gramsci. Rio de Janeiro: Graal, 1978.

04. LUZ, M.T. As instituiçōes médicas no Brasil. Rio de Janeiro: Graal, 1979.

05. PITTA, A.M. da Rocha; MEIRA, R. Comunicaçāo social em saúde e modelo assistencial. Do discurso médico hegemônico ao discurso da integridade. In: Saúde em debate. CEBES, Londrina, n.32, 1992.

06. VILAGA, M.E. Prática profissional e projeto pedagógico na Odontologia. Atualidade Odontológica, v.10, n.31, abr/jun, 1988.

\begin{tabular}{|l|l|l|l|l|l|l|}
\hline R. Fac. Odontol. & Porto Alegre & V. 33 & N. 2 & p.13-15 & DEZEMBRO & 1992 \\
\hline
\end{tabular}




\section{ANEXO}

UNIVERSIDADE FEDERAL DO RIO GRANDE DO SUL

DEPARTAMENTO DE ODONTOLOGIA PREVENTIVA E SOCIAL - DISCIPLINA DE HIGIENE BUCAL Professora Sônia Maria B. de Slavutzky

Nome:

Idade:

Sexo:

Colégio Secundário:

( ) Público ( ) Particular

Vestibular $n^{\circ}$

1. Você fez vestibular ou cursou outra faculdade?

( ) Não ( ) Sim, Qual?

2. Porque você escolheu Odontologia?

3. Você trabalha?

( ) Não

( ) Sim ( ) Serviço Público

( ) Serviço particular

4. Tens parente(s) dentista(s)? ( ) Não ( ) Sim

Qual o parentesco?

5. O que esperas com a profissão no futuro? Enumere em ordem de importância:

( ) Ter meios para viver bem, economicamente.

( ) Ser um especialista.

( ) Poder trabalhar por conta própria.

( ) Pretende ter um emprego público.

( ) Contribuir para melhoria da saúde dos brasileiros.

6. Já sabes que área pretende ser especialista?

7. Você fuma? ( ) Sim $\quad$ ( ) Não
Já fumou alguma vez? ( ) Sim () Não Por quê?

8. Você usa açúcar? ( ) Sim ( ) Não

Por quê?

9. Você consome bebidas alcoólicas? ( ) Sim ( ) Nāo

Por quê? 